\title{
Novedades de la sede web del IAPH
}

Octubre de 2003 a febrero de 2004

En febrero

> Estadísticas del Servidor Web (enero 2004) en el apartado "Sede Web"

> Becas y ayudas en el ámbito de la cultura y el patrimonio en otros organismos e instituciones

> Actualización del Calendario de Actividades de Formación en España y otros países

> Inclusión del dossier temático "Patrimonio y tecnologias de la información: bits de cultura", (PH Boletín $\left.n^{\circ} 46\right)$

> PH Boletín, $n^{\circ} 47$ (febrero 2004)

En enero

$>$ Estadisticas del Servidor Web (diciembre 2003) en el apartado "Sede Web"

> Becas y ayudas en el ámbito de la cultura y el patrimonio en otros organismos e instituciones
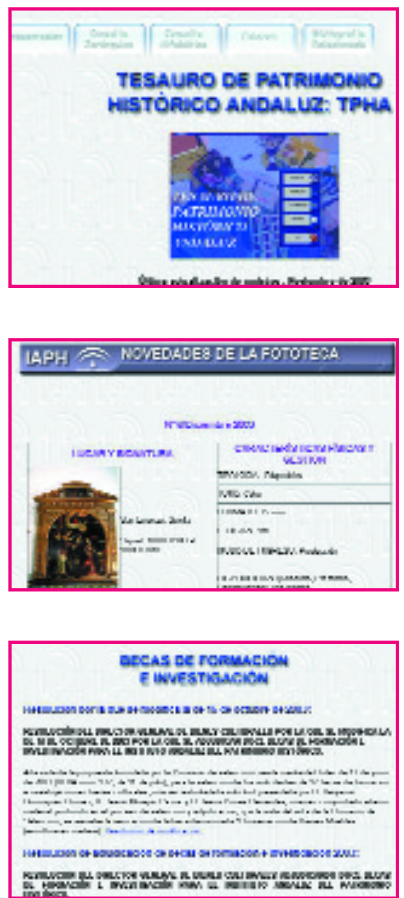

> Actualización del Calendario de Actividades de Formación en España y otros países

> Actualización del apartado "Textos-e" en Información PHA (PH Boletín, n 45, octubre 2003)

\section{En diciembre}

> Estadisticas del Servidor Web (noviembre 2003) en el apartado "Sede Web"

> Becas y ayudas en el ámbito de la cultura y el patrimonio en otros organismos e instituciones

> Nueva aplicación de consulta del Tesauro de Patrimonio Histórico Andaluz, que permite la consulta del TPHA a través de su estructura jerárquica y alfabética $>$ PH Boletín, $n^{\circ} 46$ (diciembre 2003)

$>$ Novedades de la Biblioteca (julio-noviembre 2003) > Información acerca de la V Edición del Máster en Arquitectura y Patrimonio (2004-2005)

> Novedades de la Fototeca (diciembre 2003)

En noviembre

> Estadisticas del Servidor Web correspondientes a octubre de 2003 en el apartado "Sede Web"
$>$ Novedades sobre becas y ayudas en el ámbito de la cultura y el patrimonio en otros organismos e instituciones

$>$ Actualización del Calendario de Actividades de Formación en España y otros paises

$>$ Publicación de la resolución de adjudicación de becas de formación e investigación en el IAPH 2003 $>$ Boletín de Novedades de la Fototeca (octubre 2003)

$>$ Nuevo volumen de la colección Cuadernos Técnicos denominado

"Antropología y Patrimonio: Investigación, Documentación e Intervención"

En octubre

$>$ Estadisticas del Servidor Web (septiembre 2003) en el apartado "Sede Web"

$>$ Inclusión del dossier temático "Re-conocer el patrimonio pesquero" (PH Boletín n 44)

> Programas de los cursos de especialización del programa de formación del IAPH 2003-2004

$>$ Convocatorias de másteres y posgrados de patrimonio y gestión cultural en España

> Becas y ayudas en el ámbito de la cultura y el patrimonio en otros organismos e instituciones $>$ PH Boletín, n 45 (octubre 2003)

$>$ Actualización de la información sobre Cursos de Postgrado en los que participa y colabora el IAPH $>$ Información para la adquisición de ejemplares de la Colección Cuadernos

$>$ Nuevo volumen de la colección Cuadernos Técnicos denominado

"Metodología de diagnóstico y evaluación de tratamiento para la conservación de los edificios históricos"

Susana Limón Rodriguez

Centro de Documentación del IAPH

\section{IAPH. Últimos cursos del Programa de Formación}

Taller de financiación de proyectos patrimoniales

Dirección: David Barrera Linares, gestor cultural y Pilar Tassara Andrade, EPGPC

Sede: Centro de Actividades Náuticas, Almeria

Fecha: 5 al 7 de mayo

Información:

Asociación Española de Gestores del Patrimonio

Cultural

Tel.: 913528476 y 636050636

Fax: 913115019

Correo-e.: aegpc@apdo.com

Técnicas de diagnóstico aplicadas a la conservación de los materiales de construcción en los edificios

históricos. (11 $1^{\text {a }}$ Edición)

Director: Eduardo Sebastián Pardo, Univ. de Granada
Fecha: 25 al 28 de mayo

Sede: Granada

Información:

Universidad de Granada

Dpto. de Mineralogía y Petrologia

Tel.: 958243340 Fax: 958243075

La documentación gráfica aplicada a la intervención en bienes patrimoniales Dirección: Isabel Dugo Cobacho. Centro de Documentación del IAPH

Sede: Sevilla

Fecha: 12 al 14 de mayo

Información:

C. O. de Doctores y Licenciados en B.B.A.A. de Andalucia

Tel./Fax: 954383414

Correo-e.: colbaa@teleline.es
Pautas para la gestión, organización y difusión de fondos y colecciones

fotográficas

Dirección: Asociación de Archiveros de Andalucia

Sede: Archivo de la. Diputación, Granada

Fecha: 19 al 21 de mayo

Información:

Asociación de Archiveros de Andalucia

Tel: 639244456

Web: www.sopde.es/organismos/aaa

Correo-e.: a.a.a@arrakis.es

\section{Más información}

Departamento de Formación y Comunicación IAPH Web: www.juntadeandalucia.es/cultura/iaph Correo-e.: cursos.iaph.ccul@juntadeandalucia.es 